affairs of the world; that it produces great infirmities of body; that it disqualifies him from the enjoyment of the sensual gratifications; and that it brings him within the immediate verge of death.' But let us read the whole essay, which is not unduly saddening, and remember a quotation which I personally find an excellent antidote to pontificating about age; it is 'On a toujours vingt ans dans quelque coin du coeur.'

\title{
REFERENCES
}

Anonymous. (1953). Lancet, 265, 555.

Ivy, A. C. (1945). Hygeia, Chicago, June issue.

Rolleston, H. D. (I 927). Concerning Old Age. Nature, Lond., 2 July, Suppl.

Rolleston, H. D. (r932). Medical Aspects of Old Age, London: Macmillan \& Co. Ltd.

Strachey, L. (1922). Books and Characters, French and English London: Chatto and Windus.

\section{The social medicine of old age}

\section{By C. A. Boucher, Ministry of Health, Savile Row, London, W.I}

An ageing population can be regarded as an indication of the healthiness of a nation for it is usually to be found in those countries with a high standard of living and with well-developed medical and social services. The existence in the community, however, of a large and growing number of old people can create strains and tensions which appear formidable; these may be aggravated by such factors as smaller families, dispersal of families, increasing employment for women, and an attitude of mind which maintains that the State should accept more responsibility for its dependants.

\section{The problem}

The estimated mid-r959 population of England and Wales was 45504000 including $5369000(\mathrm{I} \cdot 8 \%$ ) persons aged 65 years or more. Nearly 2 million persons, there being twice as many women as men, were aged 75 years or more. The rapidity of this development can be appreciated when it is remembered that the proportion of elderly people in the population at the beginning of this century was one in twenty-one; now it is one in nine, and it has been estimated by the Government Actuary in consultation with the Registrar General that after another two decades an additional 2 million old people will raise the proportion to one in seven. This changing pattern has resulted from a gradual fall in the birth rate since the end of the last century and from a steady fall in the death rate; more people, including the less robust, are reaching retirement age though, from that point, their expectation of life is little longer than that of their forefathers in the nineteenth century. Similar trends can be observed in most civilized countries, but the pattern in Britain shows two special features - the rate of increase in the number and proportion of old people is faster than in most other countries, and the elderly women far outnumber the men.

It is generally accepted that old people should not be isolated but should remain integrated with the rest of the population, but some will require a considerable 
amount of assistance to enable them to maintain their independence. About $96 \%$ of old people live at home and the great majority are well and active, but the Census of 195 I revealed that nearly I million, mainly women, were living entirely alone, and some local surveys have suggested that perhaps 10\% of old people at home are so infirm as to be housebound, including a small number who are bedfast. Many old people are living without effective human contacts, and some married couples can just maintain their independence by their united efforts, but the breakdown of one may provoke an unmanageable crisis for both. Though loneliness is said to be a common complaint, it is probable that the commonest causes of unhappiness are ill health and a feeling of no longer being wanted; fear of illness and accidents contributes to a feeling of insecurity. Medical science has made dramatic strides in the treatment and rehabilitation of the aged sick but has not yet made any real impact on the prevention of degenerative changes associated with old age. The real problem presented by an ageing population is that of growing infirmity unassociated with any pathological changes; it is this infirmity, resulting sometimes in immobility, which is so often responsible for the medico-social crisis which demands immediate attention and often instant admission to hospital or welfare home. The general practitioner is in the best position to detect the earliest signs of decline for many of his patients have been under his care for a long time. He finds that only a small proportion require admission to hospital but he becomes increasingly involved with those who are just beginning to fail-medically, socially, or both. He has the dual role of treatment of disease and advice on preventive measures which may delay or even obviate institutional admission.

\section{Housing}

It is often stated that a greater provision of suitably designed dwellings would prevent the social problems arising from housing that is too big or too unsuitable. The Rowntree Committee (Nuffield Foundation: Survey Committee on the Problems of Ageing and the Care of Old People, 1947) recommended that $5 \%$ of all housing should be of a type suited to and available for old people, but this figure has not yet been reached in the municipal and private building programmes between the wars and in the postwar period. Old people generally prefer to live independently, but the development of special housing often means their withdrawal from a district where they have always lived and their comparative isolation in a new environment. The association of a warden service with housing and the adaptation of central large houses to provide bed-sitting rooms has many advantages. 'Boarding out' schemes have been arranged in some areas to enable old people no longer able to live independently to reside in the homes of others willing to accept them and to give the necessary attention.

\section{Local Authority services}

An increase in the number of old people inevitably means an increase in the number of those who require assistance in order to maintain their independence. The local authority domiciliary services are expanding to meet these needs and the general 
practitioner finds that there is a high rate of consultation amongst his elderly patients. The health visitor is increasingly concerned with the health of the household as a whole and her responsibilities now include a larger element of social work than before; the needs of the elderly, particularly the very infirm and those who are living alone, are very evident to her. Nearly two-thirds of the visits paid by home nurses are to elderly patients and, without doubt, the home help is of vital importance in these services. A few old people at home, often being assisted by the home nursing or home help service, are incontinent, and the washing and drying of soiled clothes and bed linen present a problem which may prove too burdensome for the individual or his family; some local authorities and voluntary organizations have developed a special laundry service to meet this need. Some elderly patients are still admitted to hospital in a state of malnutrition, not necessarily due to poverty but in many instances to the inability to purchase the right sort of food and to prepare meals, and there is an association between this state of malnutrition and physical and mental illness; many local authorities have developed, with the help of voluntary organizations, a mobile meals service to meet this need. Many old people become housebound and immobile by reason of painful and deformed feet, and the development of chiropody as part of the National Health Service will undoubtedly make a real contribution to their happiness and to their independence; voluntary schemes have clearly shown the benefits of chiropody. All local authorities make arrangements for lending nursing equipment, and elderly people and the young chronic sick make the greatest demand; such loans may take the form of simple nursing equipment, but may also include such items as special beds, mattresses, walking aids, wheelchairs, and hoists.

\section{Welfare accommodation}

The elderly person may reach a stage where he is no longer able to maintain his independence in spite of the measures described above. Local welfare authorities are required under the National Assistance Act 1948 to provide residential accommodation for those in need of care and attention which is not otherwise available to them. Many of the large institutions are now being modernized and divided into smaller units in order to provide the type of accommodation thought necessary. In addition, since the end of the last war more than rooo small Homes of thirty to sixty residents have been opened, including I33 new Homes built for the purpose. The age and the degree of infirmity of the applicants for admission, and of the residents, are steadily rising, and the design of these welfare Homes and the nature of the staffing have to take account of their increasing frailty; stairs, for example, present the greatest difficulty. The residents register with local general practitioners, and welfare authorities appreciate that nursing care of a sort that would normally be available in their own homes is often needed. Many of the residents in the immediate period after admission benefit so rapidly that some could return to independence if suitably designed housing were available, but it is rarely found possible. Some welfare Homes accept residents for a short period in order to give temporary relief to their relatives at home, which is a very commendable practice. 


\section{Hospital service}

The pattern of the hospital population is changing. More of the general hospital beds and the out-patient clinics are being used by elderly patients. There are also $5^{8} 000$ chronic-sick beds, sited mainly in the former municipal hospitals in which have been developed geriatric units; ninety-five such units exist in Britain, including two within the curtilage of teaching hospitals, and these have shown that elderly patients will respond to rehabilitation. Only a small proportion of the patients become long-term chronic sick requiring constant nursing attention and medical supervision. Some units favour the development of out-patient clinics for the initiation of those awaiting admission and for the follow up of those recently discharged. Some units have developed 'day hospitals' which facilitate the earlier discharge of patients and delay, and sometimes obviate the need for, the admission of others. The geriatric physician is a clinician with appreciation and experience of the sociological factors influencing disease in the elderly and, to be successful, he works in close co-operation with the other services concerned with the elderly.

The mental hospitals reveal a similar picture. About $20 \%$ of the admissions are of elderly patients, and about one-third of the in-patients are of that age group, mostly women. It is generally believed that although there is no evidence of wrongful certification many of these patients could equally successfully be treated in the general hospitals, and in one hospital region it has been estimated that one-fifth of the elderly patients in mental hospitals was fit to live elsewhere, either at home or in welfare accommodation, or by transfer to chronic-sick wards. The development of psychiatric assessment units in association with general hospitals, and particularly geriatric units, has been suggested and also the establishment of annexes for longterm patients.

\section{Conclusions}

A considerable increase in the number of old people during the next two decades is forecast. It might demand a substantial expansion of institutional accommodation, but this need is difficult to estimate; continuing improvement in standards of health might reduce the institutional needs of other sections of the population and thus release more beds for the elderly, and the expanding local authority preventive services might have equally beneficial results. It has also been suggested that the higher marriage rates in recent decades and the fall in the number of marriages broken by death could reduce the future demand for institutional care, because an analysis of hospital patients showed that a high proportion of the elderly patients were single, widowed, or divorced. Nevertheless, the frailty, ill health, and social breakdown associated with old age must be regarded as the main problem and a challenge. Advice on the preservation of health in middle age and preparation for retirement may make an important contribution to health in old age. The establishment of advisory health clinics for old people may make an important contribution to health. The vast majority of old people live at home, and the key to their happiness and health lies with the general practitioners, the many valuable voluntary organiza- 
tions, the local authority services, and the provision of suitable living accommodation.

\title{
REFERENCE
}

Nuffield Foundation: Survey Committee on the Problems of Ageing and the Care of Old People. (I947). Old People; Report. Oxford: University Press.

\section{Nutritional problems encountered in social work among the elderly}

\author{
By Denise Newman, Vice-Chairman, Welfare and Clubs Committee, National Old \\ People's Welfare Council, Little Tangley, Wealdway, Caterham, Surrey
}

Many of today's medical problems clearly have a large social content, and the possibility that the converse is true is currently receiving attention. Only a few weeks ago the Central Office for Health Education called a conference to consider how far the social worker should be concerned with health education: nutritional advice to the elderly was glibly mentioned as a possible field of activity.

With the eventual implementation of the Younghusband Report on the Working Party on Social Workers in the Local Authority Health and Welfare Services this suggestion may well cease to be of merely academic interest.

The National Old People's Welfare Council (NOPWC) is particularly grateful to The Nutrition Society for arranging today's symposium. It will help to focus interest on an aspect of work for the elderly which has so far received insufficient attention.

It would not come amiss here if I outlined the dilemma which prompted the Council to approach the Ministry of Health with the suggestion that an advisory group be set up to consider nutritional policy in respect of the elderly.

The function of the National Old People's Welfare Council is to co-ordinate in its field the work of statutory and voluntary agencies and it has some 57 county and I 500 local committees for this purpose.

Reports from voluntary workers visiting the housebound aged expressed concern at the poor standards of feeding often found. Various reasons were given: some of the old people were unaware of the importance of feeding, with others shortage of money apparently prevented them from having adequate meals, and some showed disinclination to bother with food through physical infirmity or general apathy.

Because of such findings several local old people's welfare committees produced food advisory leaflets, the value of which was questionable. Some contained information and precepts which shocked dietitians.

The British Dietetic Association was invited to collaborate in the preparation of suitable basic advice. A set of notes for speakers was published, for use where dietitians or other informed persons were not available to give talks in old people's clubs or to groups of voluntary workers. 